the pig by Mayer in 1825 and by Bang in 1876 in a female patient who died of volvulus. It was reported in the living by Hahn in 1899 . Since then there have been a number of reports, mostly of single cases, but Doub and Shea (1960) described 16 cases in their practice.

Despite those records the natural history is badly documented. Jones (1948) described a case in which laparotomy had shown no cysts. Two and a half years later repeated laparotomy showed pneumatosis of the colon and mesentery. Griffiths (1955) described a case in which laparotomy in 1946 showed no cysts ; colonic symptoms began one year later-for example, blood and mucus per rectum-and gradually increased, and by 1949 the condition was demonstrated by sigmoidoscopy and $x$-ray examination. The present patient was probably free of cysts in 1959 (though only a part of the colon was shown on barium studies) but had gross disease in 1962. It would therefore seem that the disease is fairly slow in developing, which is supported by the gross enlargement of the colon in established cases.

The subsequent history is also badly documented. Koss (1952) stated that "there is considerable evidence that the cysts may disappear spontaneously," and cited a number of authors, but these all appear to be cysts of the small intestine. Doub and Shea (1960) described 16 cases of colonic involvement

\section{Death from Vertebral Artery Thrombosis in Rheumatoid Arthritis}

\author{
Brit. med. F., 1968, 2, 537-538
}

Our purpose is to describe the case of a middle-aged woman with arthritis mutilans who died 30 hours after lapsing into coma. It was shown at post-mortem examination that she had extensive necrosis of the medulla and mid-brain as well as of the right lobe of the cerebellum. This was associated with thrombosis of both vertebral arteries and long-standing severe disorganization of the upper cervical spine with atlantoaxial dislocation.

Death is a rare but known occurrence where rheumatoid arthritis involves the cervical spine. Death from compression of the medulla by a dislocated odontoid process was first described by Davis and Markley (1951) and more recently by Martel and Abel (1963). Death from thrombosis of the vertebral arteries complicating rheumatoid disease of the cervical spine does not appear to have been described before.

\section{CAse History}

This patient was 53 years old when she died, having suffered from severe erosive seropositive rheumatoid disease, which had progressed inexorably since its onset when she was 21 years old. By the time she had reached her 38th year the disease involved all the joints of the limbs, and there was radiological evidence of rheumatoid involvement of the cervical spine. At the age of 40 she was given corticosteroids by mouth to control an episcleritis, and these drugs were continued until she died.

Her husband reported that she had had occasional blackouts in the year before she died, with occipital headaches and morning nausea. Thirty hours before her death she was found unconscious on the bathroom floor.

On admission to hospital she was in deep coma with a flaccid left arm and left leg. Her temperature was $103^{\circ} \mathrm{F}$. $\left(39.4^{\circ} \mathrm{C}\right.$.) and she was hyperventilating. Both plantar responses were extensor, and the clinical impression was of a serious right-sided stroke. Examination showed that the cerebrospinal fluid was normal, and the white cell count was $17,800 / \mathrm{cu}$. $\mathrm{mm}$. ( $92 \%$ polymorphonuclear neutrophils). without complications and stated that the cysts may regress, but gave no long follow-up. The case described above resolved symptomatically in one year and completely in five years.

\section{H. DENDY MOORE, M.C., F.R.C.S., F.R.C.S.ED., Surgeon, Royal Devon and Exeter Hospital and Exeter City Hospital.}

\section{REFERENCES}

Bang, B. L. F. (1876). Nord. med. Ark., 8, 1.

Bubis, J. L., and Swanbeck, C. E. (1922). Ann. Surg., 75, 620

Burn, J. I., and Jones, B. S. (1961). Brit. med. 7., 2, 747

Creese, P." G. (1951) Gastroenterology, 19, 75.

Doub, H. P., and Shea, J. J. (1960). F. Amer. med. Ass., 172, 1238.

Friedmann, I. (1949). F. clin. Path., 2, 91.

Griffiths, G. J. (1955). Lancet, $2,905$.

Hahn, E. (1899). Disch. med. W schr., 25, 657.

Jones, J. D. T. (1948). Brit. F. Surg., 36, 49.

Koss, L. G. (1952). Arch. Path., 53, 523.

Marshak, R. H., Blum, S. D., and Eliasoph, J. (1956). 7. Amer. med.

Ass., 161, 1626.
Mayer, J. (1825). \%. prakt. Heilk., 61, 67.

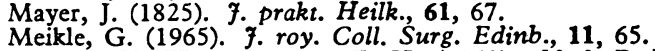

Morgan, H. W., and Barg, E. H. (1950). Med. Radiogr. Photogr., 26, 128 .

Nitch, C. A. R. (1924). Brit. F. Surg., 11, 714.

Somerville, P. (1951). Lancet, 2, 1160.

Witkowski, L. J., Pontius, G. V., and Anderson, R. E. (1955). Surgery, 37, 959.

She did not recover consciousness, and died 30 hours after the onset of coma.

\section{POST-MORTEM EXAMINATION}

The most obvious abnormality of the external aspect of the brain was that the right hemisphere of the cerebellum was necrotic. The right half of the medulla was softened and the external surface of the medulla had a concavity on its ventral aspect where normally there is a convexity. The right superior cerebellar and anterior inferior cerebellar arteries were thrombosed. On cutting through the mid-brain an area of softening with punctate haemorrhages was revealed in the right tectal region extending up to the lower border of the right red nucleus, and, in its lower extremity, becoming confluent with the necrotic area in the medulla and pons. When the brain had been removed a hard lump formed by the tip of the odontoid process could be seen projecting upward through the foramen magnum (Fig. 1).

The first five cervical vertebrae were removed from the cadaver as a block with part of the occipital bone surrounding the foramen magnum. When these bones were divided coronally, in a plane just

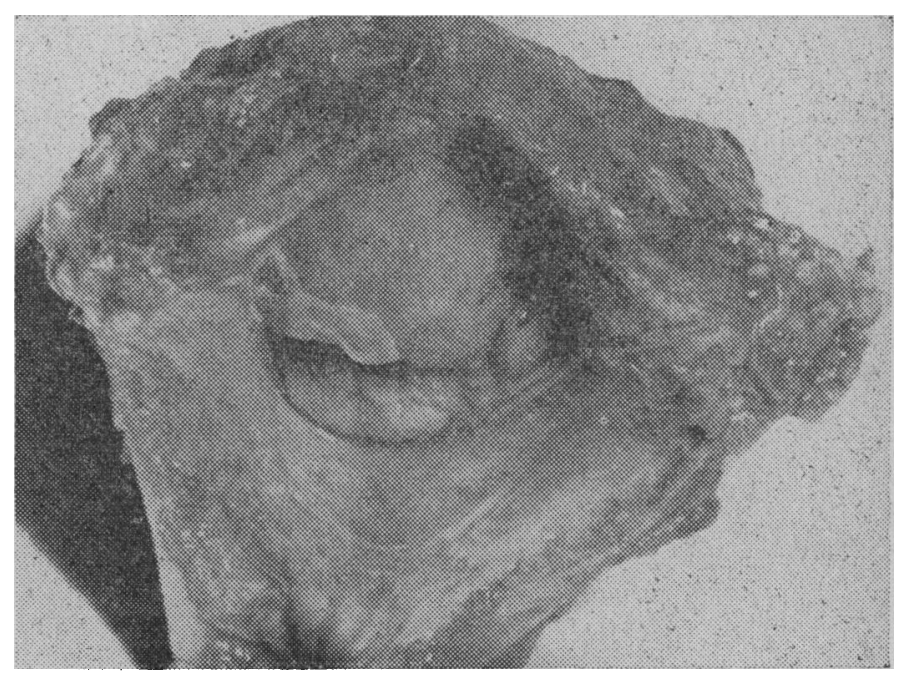

FIG. 1.-Foramen magnum, with part of the occipital bone viewed from above. The odontoid process bulges posteriorly and upwards into the foramen magnum, compressing the medulla. 
posterior to the vertebral bodies and odontoid process, it was evident that there was severe disorganization of bone and joints. On the right side the lateral mass of the atlas had disappeared, and on the left side the pedicle of the axis for articulation with the lateral mass of the atlas had collapsed. There was severe atlanto-axial dislocation, which appeared to be the result of subsidence of the occipital condyles due to destruction of the bone and joints of the atlas and axis. The transverse ligament of the atlas appeared to have been destroyed, as it could not be identified. There was severe distortion and destruction of the joints between the articular processes of the vertebrae and bony ankylosis between the vertebral bodies.

Both vertebral arteries were blocked by thrombus at their upper ends where they followed a tortuous course among the disorganized collapsed remnants of the atlas and axis. Other findings were cortical atrophy of the adrenal glands and chronic pyelonephritis with bilateral renal calculi.

\section{Discussion}

Vertebral artery obstruction, usually partial and sometimes intermittent, is now well recognized in patients with cervical spondylosis (Sheehan, Bauer, and Meyer, 1960 ; Hardin, 1965). The bony changes, with ligamentous disruption, can be very much more severe in the cervical spine in rheumatoid disease than in cervical spondylosis. It is therefore surprising that
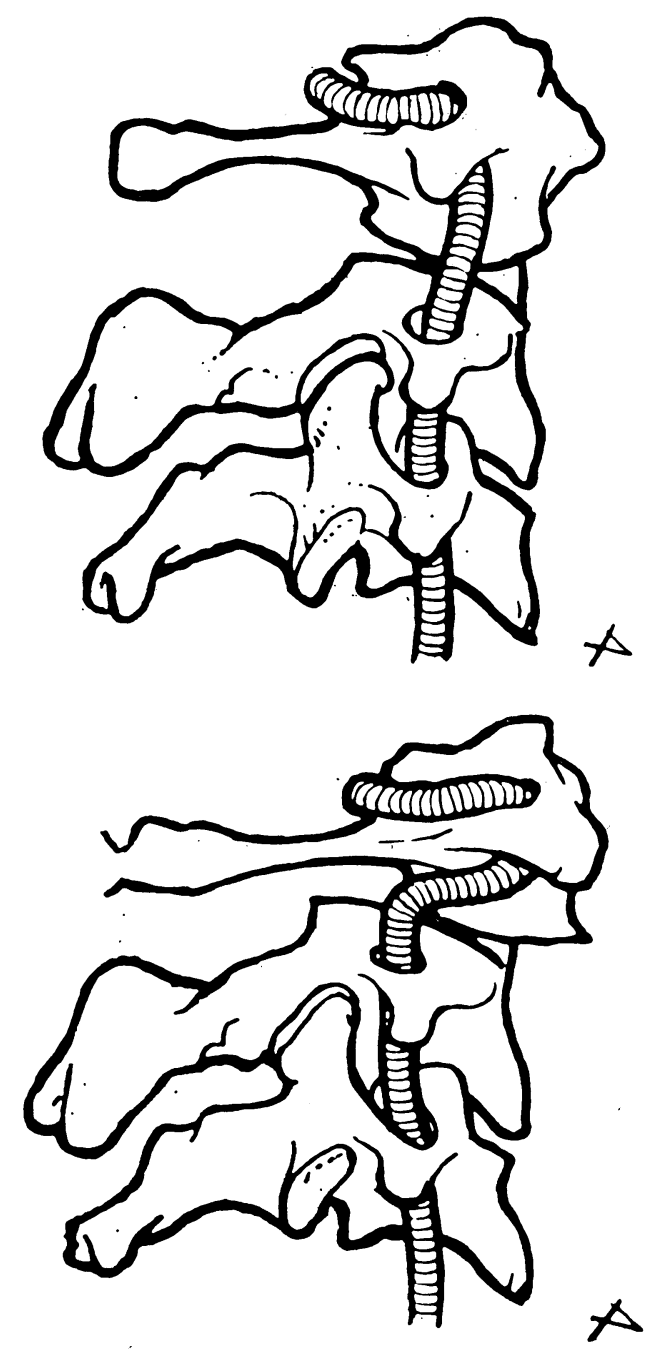
Fig. 2.-Drawing by Mr. Charles Pierce, comparing the normal course
of the vertebral artery (above) with the course of the vertebral artery in the presence of atlanto-axial subluxation (below). vertebral artery involvement in patients with rheumatoid disease of the cervical spine has not been described before.

The vertebral artery has a peculiarly tortuous course, as, after passing upwards through the transverse processes of the upper six cervical vertebrae, it winds behind the lateral mass of the atlas to pierce the atlanto-occipital membrane posteriorly. Atlanto-axial dislocation will exaggerate this tortuosity and the artery would be particularly apt to be caught up in any bony or disc disorganization at this site (Fig. 2).

Even in the normal cervical spine the vertebral artery is in a vulnerable position. Ford and Clark (1956), in describing cases of thrombosis of the basilar artery due to manipulation of the neck, report that a previously healthy man of 32 died 24 hours after losing consciousness during neck manipulation by a chiropractor. He was found to have thrombosed the basilar and right posterior inferior cerebellar arteries, with infarction of the cerebellar peduncle and the right cerebellar hemisphere.

Rotation of the head about the odontoid peg swings one side of the atlas forward and the other side back. As the vertebral artery has a double hairpin bend, as shown in Fig. 2, there is the possibility of simultaneous obstruction to both vertebral arteries on rotation of the head.

Ford (1952) described the case of a boy of 17 with excessive mobility at the atlanto-axial joint due to congenital absence of the odontoid peg who presented with symptoms suggestive of intermittent obstruction of the vertebral arteries. This degree of excessive mobility at the atlanto-axial joint also occurs in rheumatoid involvement of the cervical spine, and might similarly be expected to obstruct the vertebral arteries. In the case described above it is possible that the patient, who had severe limitation of elbow and shoulder movements, obliterated her vertebral arteries in rotating her head to clean her teeth. Be this as it may, it is possible that this type of involvement of the vertebral arteries has occurred in patients with rheumatoid disease who are thought to have suffered a more common kind of stroke.

The safe and well-accepted operation of posterior occipitoaxial fusion is occasionally carried out for atlanto-axial instability with signs of medullary compression. If arch angiography can show vertebral artery obstruction during gentle rotation of the head in a patient with rheumatoid disease of the cervical spine, in whom symptoms of basilar artery insufficiency are present, then perhaps posterior fusion should be considered.

We thank Dr. F. H. Scadding and Dr. A. C. Boyle for allowing us to publish details of this patient, and Dr. J. G. Bearn for the loan of Fig. 2.

F. W. S. WEBB, * M.B., B.CHIR., M.R.C.P. J. A. HICKMAN, M.B., B.CHIR., M.R.C.P., Registrars, the Middlesex Hospital, London W.1.

D. ST. J. BREW, M.B., B.S., M.C.PATH., Senior Lecturer, the Bland Sutton Institute of Pathology, London W.1.

* Present address: The Hammersmith Hospital, London W.12.

\section{REFERENCES}

Davis, F. W., and Markley, H. E. (1951). Ann. intern. Med., 35, 451. Ford, F. R. (1952). Bull. Fohns Hopk. Hosp., 91, 168 Ford, F. R., and Clark, D. (1956). Bull. fohns Hopk. Hosp., 98, 37. Hardin, C. A. (1965). Arch. Surg., 90, 629.

Martel, W., and Abel, M. R. (1963). Arthr. and Rheum., 6, 224. Sheehan, S., Bauer, R. B., and Meyer, J. S. (1960). Neurology (Minneap.), 10, 968. 